\title{
Technical Note - Lateral Approach to the Lumbar Spine for the Removal of Interbody Cages
}

\author{
Marc Moisi $^{1}$, Jeni Page ${ }^{2}$, David Paulson ${ }^{3}$, Rod J. Oskouian ${ }^{4}$ \\ 1. Neurosurgery, Seattle Science Foundation 2. Neurosurgery, Swedish Neuroscience Institute 3. \\ Neurosurgey, Swedish Neuroscience Institute 4. Neurosurgery, Complex Spine, Swedish Neuroscience \\ Institute
}

$\square$ Corresponding author: Marc Moisi, moisimd@gmail.com

Disclosures can be found in Additional Information at the end of the article

\section{Abstract}

Revision surgery to address the migration or fracture of a lumbar interbody cage can be technically challenging. Scar tissue and fibrosis, among other anatomic barriers, can make removal of the cage a complicated procedure, potentially increasing postoperative pain as well as the probability of neurologic deficits. Use of the lateral surgical technique for removal of the cage can avoid these potential complications. In this case report, we describe the removal of interbody cages through a lateral approach in three patients without the necessity of additional posterior hardware revision.

\section{Categories: Neurosurgery}

Keywords: lateral interbody fusion, pseudoarthrosis, cage removal, interbody cage migration, revision surgery

Received 04/03/2015

Review began 04/05/2015

Review ended 04/29/2015

Published 05/11/2015

C) Copyright 2015

Moisi et al. This is an open access article distributed under the terms of the Creative Commons Attribution License CC-BY 3.0., which permits unrestricted use, distribution, and reproduction in any medium, provided the original author and source are credited.

\section{Introduction}

A lateral interbody fusion is a minimally invasive, transpsoas, retroperitoneal surgical approach to the thoracic and lumbar intervertebral disc space [1]. Use of this technique in revision surgery can reduce the risk of complications more common with traditional approaches, both anterior and posterior [2-3]. Particularly in cases of interbody cage migration, cage fracture, or those with failure to fuse, this technique allows direct access to the cage while avoiding scar tissue and epidural fibrosis. However, few studies have been published discussing this approach for cage removal not requiring posterior hardware revision [3-4]. In this case report, we discuss our experience with the lateral retrieval of interbody cages that have migrated, fractured, or not fused, and subsequently required surgical intervention but did not require posterior hardware revision.

\section{Technical Report}

Approval for this study was obtained from the Swedish Institutional Review Board (IRB \#FWA00000544). Informed patient consent was obtained from all subjects.

\section{Representative cases}

Presentation

The first patient reviewed was a 71-year-old female who fell six weeks postoperatively 


\section{Cureus}

following a transforaminal lumbar interbody fusion (TLIF) at L3-4. Subsequently, she developed lumbar and radicular pain. Computed tomography (CT) demonstrated displacement of the interbody cage into the spinal canal causing severe central canal stenosis (Figure 1).

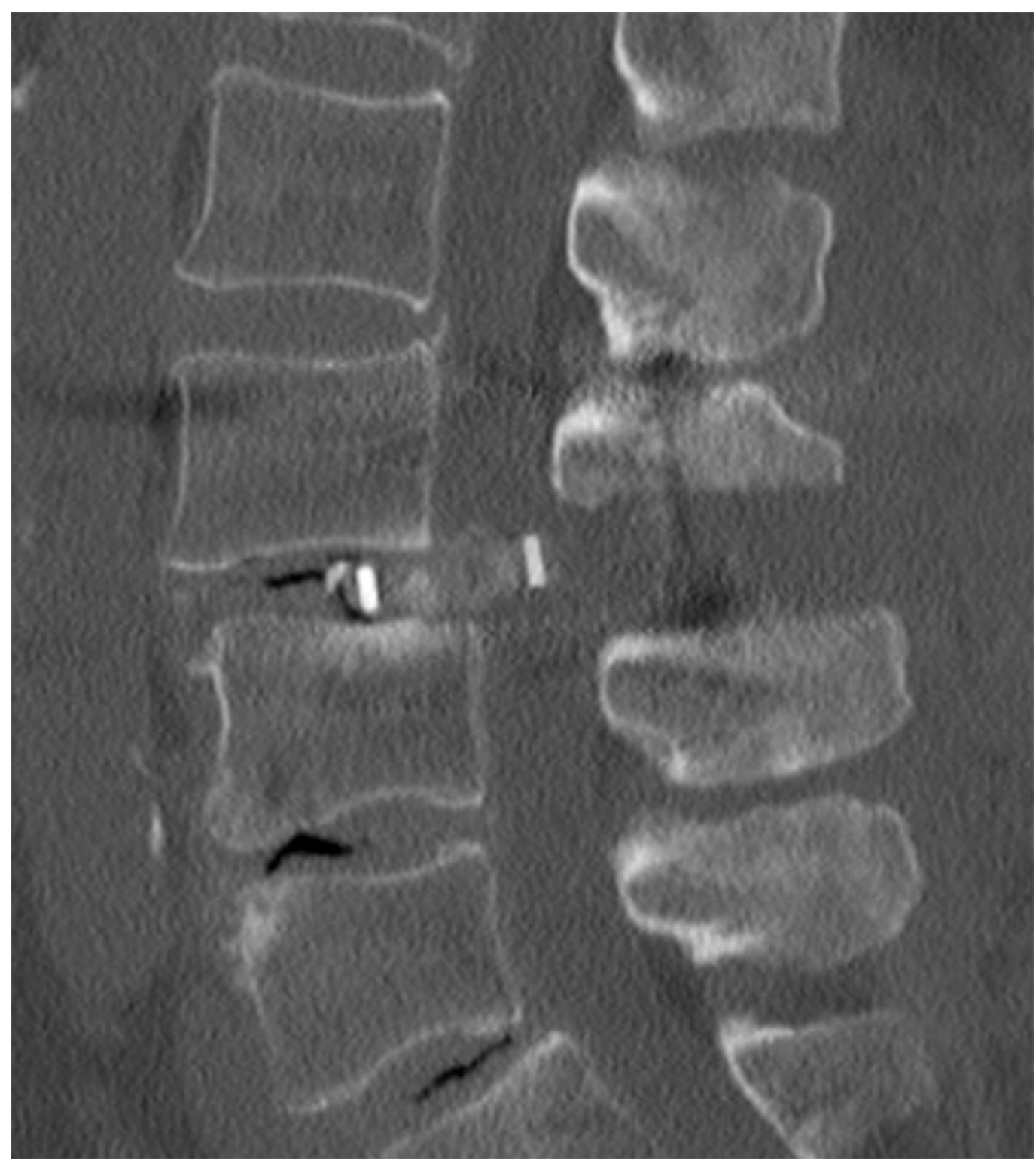

\section{FIGURE 1: Cage Migration}

Computed tomography (CT) demonstrating migration and displacement of the interbody cage into the spinal canal causing severe central canal stenosis.

In the second patient case, a 52-year-old female was evaluated in clinic with symptoms of significant neurogenic claudication, radicular pain, and lower extremity weakness two years status post posterior lumbar interbody fusion at L3-4. CT imaging revealed a fracture of the interbody cage and its subsequent migration into the spinal cord (Figure 2). 


\section{Cureus}

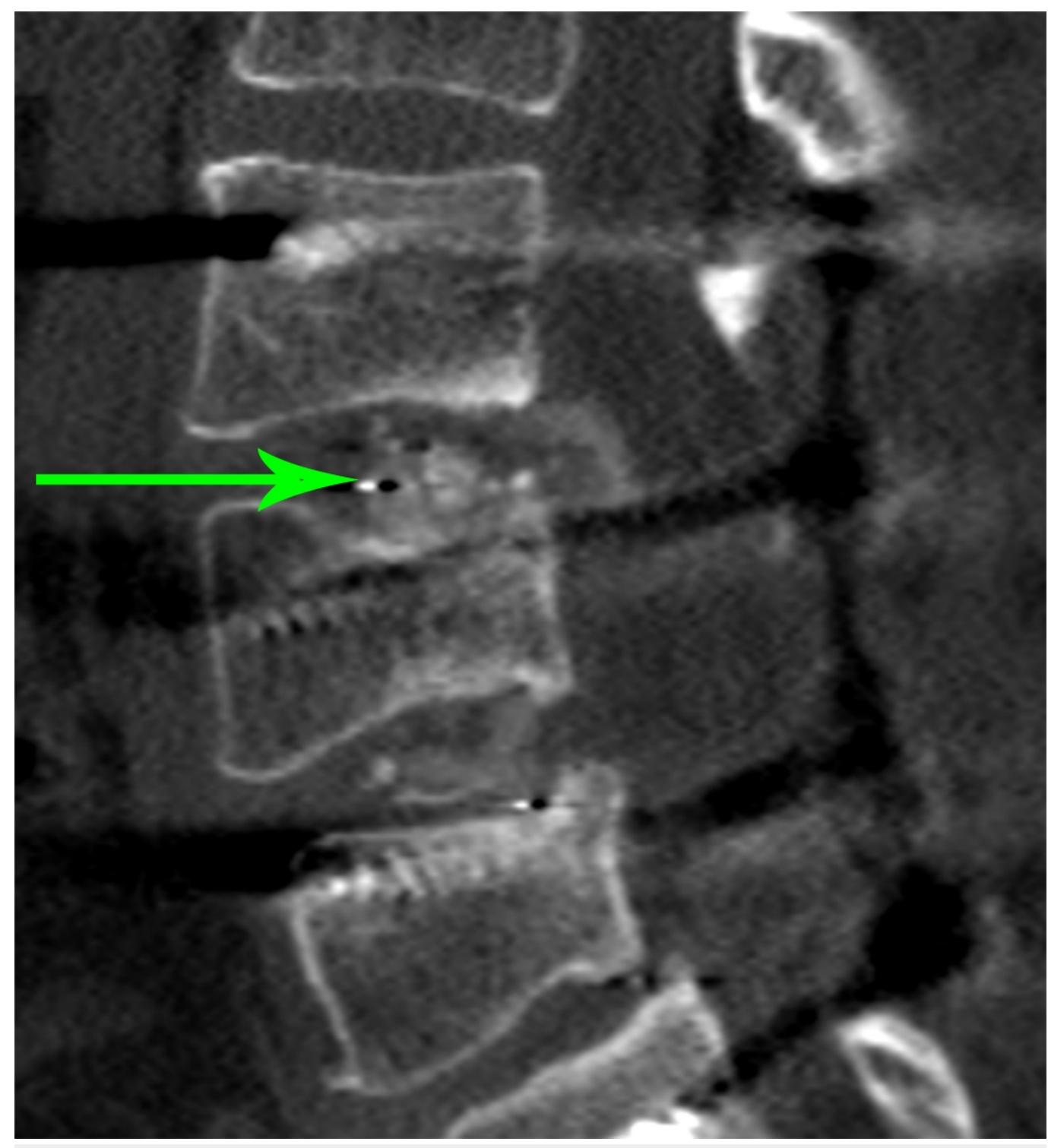

\section{FIGURE 2: Cage Fracture and Migration}

CT imaging reveals a fracture of the interbody cage and its subsequent migration into the spinal cord.

The third patient reviewed was a 50-year-old female who presented for evaluation of increasing back pain one-year status-post L2 to L5 fusion. CT imaging demonstrated with pseudoarthrosis of the (TLIF) interbody cage at the L3-4 level with subsidence causing significant lumbar stenosis.

\section{Operative Technique}

Once docked on the lateral disc space, we used an osteotome to go above and below the cage as well as along the end plate (Figure 3). 


\section{Cureus}

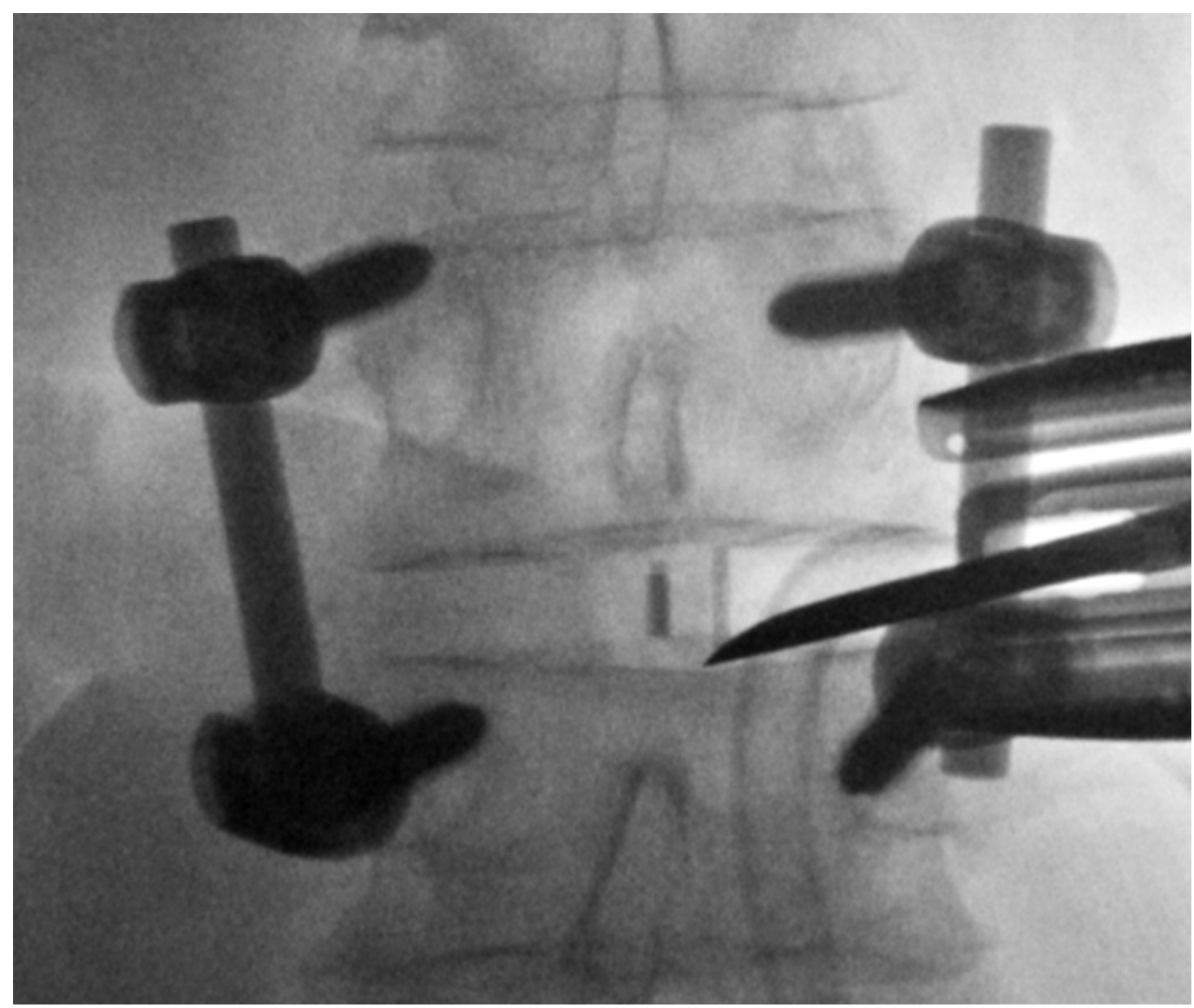

\section{FIGURE 3: Loosening of the Cage}

An osteotome can be seen approaching the disc space laterally along the inferior end plate. This is done in order to loosen the cage.

This was completed in order to loosen and remove the interbody cage. In some instances, a straight and a curved curette were used to loosen the cage from scar tissue and the end plates. Once the cage was properly loosened, a hook or pituitary with teeth was inserted to grab the cage allowing it to be withdrawn from the interspace (Figure 4). 


\section{Cureus}

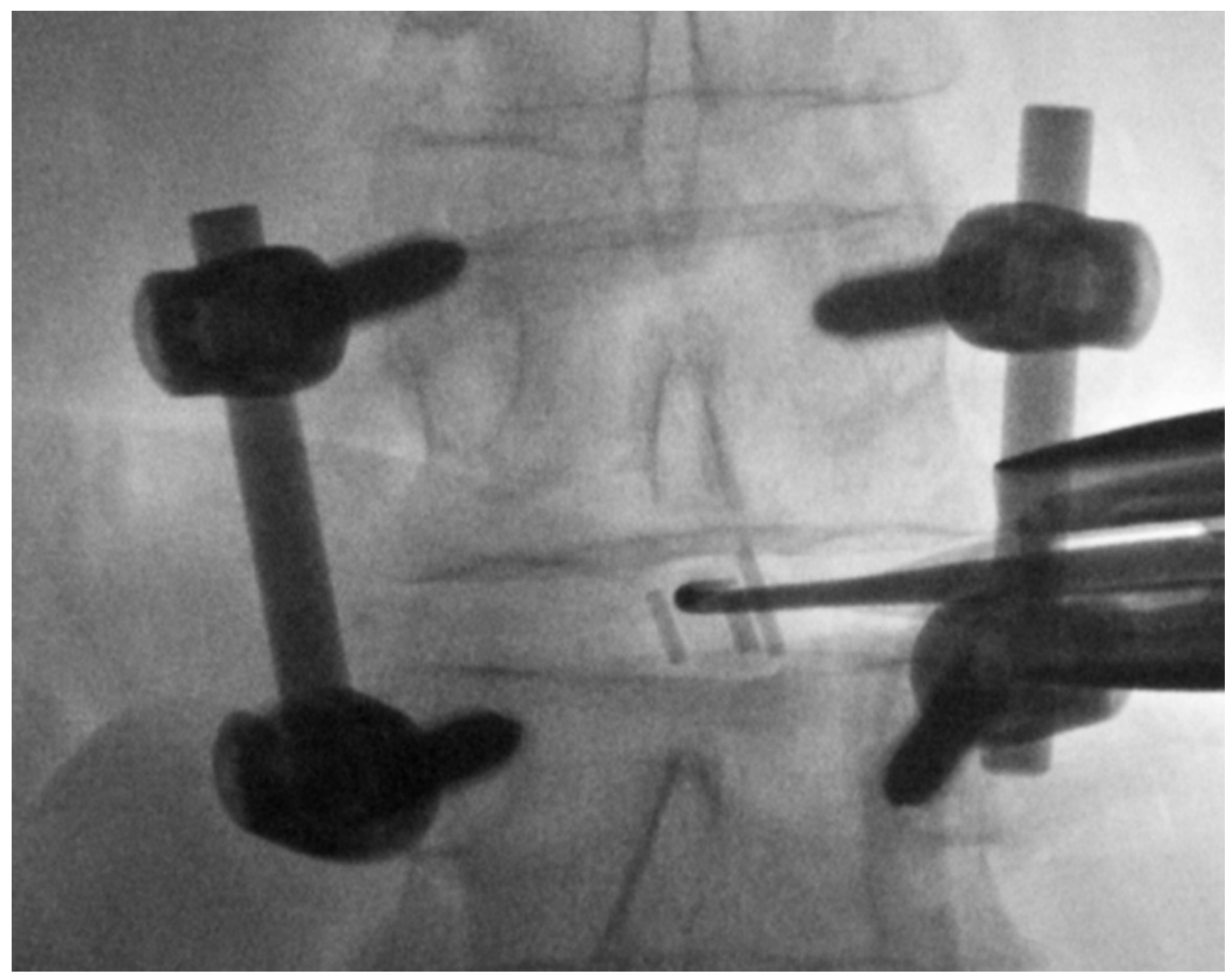

\section{FIGURE 4: Cage Retrieval}

After the cage is loosened, a hook or pituitary with teeth is used to retrieve the material.

In all three cases, once the cages were confirmed by fluoroscopy to have been removed, the disc space was then prepared in the usual fashion, a new cage was inserted, and a lateral interbody fusion was performed. Although there are some constraints placed on the size of the new cage since there is already posterior fixation, the goal of this revision surgery is not to maintain a significant amount of added indirect decompression, but to provide stabilization to the anterior column.

\section{Discussion}

Revision surgery can be technically challenging with epidural fibrosis and scarring from prior surgical interventions making exposures complex and leading to increased risk of an incidental durotomy and nerve root injury [5-6]. However, removal of failed hardware is frequently necessary when there is subsequent compression of neural elements and spinal cord resulting in lower extremity pain and weakness [7]. Interbody cages can migrate or a fractured piece can displace in the anterior, posterior, or lateral directions. Historically, removal of these cages has been completed in the traditional approaches through an anterior or posterior incision.

The anterior approach for removal of an interbody cage poses similar risks to those of the initial surgery, as well as possible complications related to fibrosis. It can be an appealing technique as it preserves the posterior paravertebral muscles and ligaments, but carries multiple risks, including retrograde ejaculation, ileus, abdominal muscle weakness, and lymphocele [8-11]. Furthermore, the anterior approach, due to its close proximity to the great vessels, can lead to significant vascular injury [11-12]. Vascular injury poses particularly high risks with revision 
surgery due to the presence of retroperitoneal fibrosis [12-14]. Even with the assistance of access surgeons, one study found vascular injury occurred in $57 \%$ of their cases [15]. This same study concluded both blood loss and length of stay were higher with anterior revision surgery. Despite these risks, cage displacement location or patient anatomy may warrant the anterior approach, and while the cage can be successfully revised with this technique, there is frequently a need for more extensive surgery. Glassman, et al. described an anterior technique for removal of the cage, which was successful [16]. However, this procedure ultimately required a partial vertebral body resection. Oh, et al. similarly used the anterior approach for removal and replacement of the interbody cage, but in this particular study, the patient also required a posterior approach for revision of the segmental instrumentation [17].

Removal of the interbody cage from a posterior technique can be difficult for multiple reasons. Epidural fibrosis from prior surgery can alter the natural planes and anatomic landmarks making location identification challenging [6]. This in turn can lead to increased dural retraction and nerve root mobilization with the exposure [18-19]. Additionally, in cases where stripping of the paravertebral musculature is necessary, the retraumatization to the posterior structures can increase risk of significant postoperative myofascial pain, bleeding, infection, and nerve injury up to $15-30 \%[5,19]$. To avoid these complications, some studies have evaluated implementing the posterior minimally invasive technique for revision [6]. However, Selznick, et al. suggests this approach, particularly for revision of a lumbar interbody fusion, harbors a significantly higher risk of a cerebrospinal fluid (CSF) leak [6]. Furthermore, these studies did not examine revision of the interbody cage alone.

The introduction of the lateral approach provided an access to the anterior lumbar spine without the need of an access surgeon [11]. While the technique has been successfully utilized for multiple spinal conditions, the approach has gained popularity in revision surgery because it involves navigating virgin tissue and thus avoiding the complications associated with traditional exposures [11]. Besides the ease and direct minimally invasive access of the approach, the technique increases safety to an area that has been previously disturbed with past surgical attempts [11].

The lateral approach is not without complications. Due to the nature of the muscle splitting approach through the psoas, as well as the close proximity to the lumbar plexus, transient nerve injury can occur causing temporary pain, weakness, or numbness [11, 20-23]. If injured, these nerves can cause detrimental consequences, making the use of neurophysiologic monitoring a necessity [24-25]. Hip flexor weakness and transient anterior thigh sensory changes have been reported in $28 \%$ and $18 \%$ of the patients, respectively, generally resolving in the early postoperative period [26]. For this reason, a thorough understanding of the lateral anatomy, as well as a good understanding of the technique, will help to avoid these types of complications [27-28].

Also of consideration is when the technique can be effectively used. Interbody cage position and displacement can play a crucial role in this process. This technique can be used to retrieve cages previously placed through posterior, anterior, and lateral approaches, but a careful understanding of the anatomy and pitfalls is necessary. When the cage is too posterior with significant migration into the canal, there is an increased risk of pushing it further posterior and causing a cerebrospinal fluid (CSF) leak. Similarly, if the cage is too anterior, the great vessels are at risk to be injured. Close proximity to the great vessels does not exclude the lateral approach but does warrant close evaluation. CT imaging as well as lateral/anteroposterior (AP) radiographs completed prior to proceeding with surgery can help to assure the cage is accessible [11]. Furthermore, the lateral approach may not be feasible depending on the anatomy of the patient. In patients with a high iliac crest, the crest impedes access to the disc space. Thus, the L5-S1 level is not accessible, and on occasion, the L4-5 level cannot be reached $[26,28]$. 


\section{Conclusions}

When the decision to remove an interbody cage is made in which a posterior hardware revision is not indicated, use of the lateral technique is an option that provides great results with all the cases discussed leading to fusion and resolution of preoperative symptoms. Surgeons considering this approach should have a good understanding of the lateral anatomy as well as recognize indications for this procedure with revision surgery. Patient cases should be examined on an individualized basis with special consideration given to cage location and patient anatomy.

\section{Additional Information}

\section{Disclosures}

Human subjects: Consent was obtained by all participants in this study. Swedish Institutional Review Board issued approval FWA00000544. Animal subjects: All authors have confirmed that this study did not involve animal subjects or tissue. Conflicts of interest: In compliance with the ICMJE uniform disclosure form, all authors declare the following: Payment/services info: All authors have declared that no financial support was received from any organization for the submitted work. Financial relationships: All authors have declared that they have no financial relationships at present or within the previous three years with any organizations that might have an interest in the submitted work. Other relationships: All authors have declared that there are no other relationships or activities that could appear to have influenced the submitted work.

\section{References}

1. Ozgur BM: Extreme Lateral Interbody Fusion (XLIF): a novel surgical technique for anterior lumbar interbody fusion. Spine J. 2006, 6:435-43. 10.1016/j.spinee.2005.08.012

2. Cheng WK, Jadhav V, Palmer DK: A novel modification for removal of the polyethylene core in artificial disc retrieval using a transpsoas minimally invasive technique. J Neurosurg Spine. 2011, 14:466-9. 10.3171/2010.12.SPINE09429

3. Daffner SD, Wang JC: Migrated XLIF cage: Case report and discussion of surgical technique . Orthopedics. 2010, 33:518. 10.3928/01477447-20100526-21

4. Pimenta L, Díaz RC, Guerrero LG: Charité lumbar artificial disc retrieval: use of a lateral minimally invasive technique. Technical note. J Neurosurg Spine. 2006, 5:556-61. 10.3171/spi.2006.5.6.556

5. Eichholz KM, Ryken TC: Complications of revision spinal surgery. Neurosurg Focus. 2003, 15:E1. 10.3171/foc.2003.15.3.1

6. Selznick LA, Shamji MF, Isaacs RE: Minimally invasive interbody fusion for revision lumbar surgery: technical feasibility and safety. J Spinal Disord Tech. 2009, 22:207-13. 10.1097/BSD.0b013e318169026f

7. Aoki Y, Yamagata M, Nakajima F, Ikeda Y, Takahashi K: Posterior migration of fusion cages in degenerative lumbar disease treated with transforaminal lumbar interbody fusion: a report of three patients. Spine (Phila Pa 1976). 2009, 34:E54-8. 10.1097/BRS.0b013e3181918aae

8. Lindley EM, McBeth ZL, Henry SE, Cooley R, Burger EL, Cain CM, Patel VV: Retrograde ejaculation after anterior lumbar spine surgery. Spine (Phila Pa 1976). 2012, 37:1785-9. 10.1097/BRS.0b013e31825752bc

9. Patel AA, Spiker WR, Daubs MD, Brodke DS, Cheng I, Glasgow RE: Retroperitoneal lymphocele after anterior spinal surgery. Spine (Phila Pa 1976). 2008, 33:648-52.

10.1097/BRS.0b013e31817c6ced

10. Than KD, Wang AC, Rahman SU, Wilson TJ, Valdivia JM, Park P, La Marca F: Complication avoidance and management in anterior lumbar interbody fusion. Neurosurg Focus. 2011, 31:6. 10.3171/2011.7.FOCUS11141

11. Pimenta L, Marchi L, Oliviera L, Howell KM: History of lateral approach. Extreme Lateral Interbody Fusion (XLIF). Goodrich JA, Volcan IJ (ed): Quality Medical Publishing, Inc, St. Louis; 2013. 3-11. 
12. Rothenfluh DA, Koenig M, Stokes OM, Behrbalk E, Boszczyk BM: Access-related complications in anterior lumbar surgery in patients over 60 years of age. Eur Spine J. 2014, 23:S86-92. 10.1007/s00586-014-3211-4

13. Chan FL, Chow SP: Retroperitoneal fibrosis after anterior spinal fusion . Clin Radiol. 1983, 34:331-5. 10.1016/S0009-9260(83)80354-7

14. Jeon SH, Choi WG, Lee SH: Anterior revision of a dislocated ProDisc prosthesis at the L4-5 level. J Spinal Disord Tech. 2008, 21:448-50. 10.1097/BSD.0b013e3181633a32

15. Nguyen HV, Akbarnia BA, van Dam BE, Raiszadeh K, Bagheri R, Canale S, Sylvain GM, Barone R, Bench G: Anterior exposure of the spine for removal of lumbar interbody devices and implants. Spine (Phila Pa 1976). 2006, 31:2449-53. 10.1097/01.brs.0000240271.39583.b6

16. Glassman SD, Johnson JR, Raque G, Puno RM, Dimar JR: Management of iatrogenic spinal stenosis complicating placement of a fusion cage. A case report. Spine (Phila Pa 1976). 1996, 21:2383-6. 10.1097/00007632-199610150-00018

17. Oh HS, Lee SH, Hong SW: Anterior dislodgement of a fusion cage after transforaminal lumbar interbody fusion for the treatment of isthmic spondylolisthesis. J Korean Neurosurg Soc. 2013, 54:128-31. 10.3340/jkns.2013.54.2.128

18. Chen L, Yang H, Tang T: Cage migration in spondylolisthesis treated with posterior lumbar interbody fusion using BAK cages. Spine (Phila Pa 1976). 2005, 30:2171-5. 10.1097/01.brs.0000180402.50500.5b

19. Kim CH, Chung CK, Jahng TA, Yang HJ, Son YJ: Surgical outcome of percutaneous endoscopic interlaminar lumbar discectomy for recurrent disk herniation after open diskectomy. J Spinal Disord Tech. 2012, 25:E125-33. 10.1097/BSD.0b013e31825bd111

20. Hrabalek L, Adamus M, Gryga A, Wanek T, Tucek P: A comparison of complication rate between anterior and lateral approaches to the lumbar spine. Biomed Pap Med Fac Univ Palacky Olomouc Czech Repub. 2014, 158:127-32. 10.5507/bp.2012.079

21. Malone KT, Rodgers WB, Osio G, Smith WD: Anatomic considerations in XLIF ${ }^{\circledR}$. Extreme Lateral Interbody Fusion (XLIF). Goodrich JA, Volcan IJ (ed): Quality Medical Publishing, Inc, St. Louis; 2013. 79-90.

22. Mayer HM: A new microsurgical technique for minimally invasive anterior lumbar interbody fusion. Spine (Phila Pa 1976). 1997, 22:691-9. 10.1097/00007632-199703150-00023

23. Rodgers WB, Gerber EJ, Patterson J: Intraoperative and early postoperative complications in extreme lateral interbody fusion: an analysis of 600 cases. Spine (Phila Pa 1976). 2011, 36:2632. 10.1097/BRS.0b013e3181e1040a

24. Jahangiri FR, Sherman JH, Holmberg A, Louis R, Elias J, Vega-Bermudez F: Protecting the genitofemoral nerve during direct/extreme lateral interbody fusion (DLIF/XLIF) procedures. Am J Electroneurodiagnostic Technol. 2010, 50:321-35.

25. Taylor WR, O'Brien RA, Cornwall GB, Malone ME, Cohen BA, Atwater J: The role of integrated neurophysiologic monitoring. Extreme Lateral Interbody Fusion (XLIF). Goodrich JA, Volcan IJ (ed): Quality Medical Publishing, Inc, St. Louis; 2013. 45-57.

26. Rodgers WB, Uribe JS: Complications and their avoidance in XLIF® ${ }^{\circledR}$. Extreme Lateral Interbody Fusion (XLIF). Goodrich JA, Volcan IJ (ed): Quality Medical Publishing, Inc, St. Louis; 2013. 179-197.

27. Dawkar E, Uribe JS: Anatomy of the lateral lumbar approach: Studies of the psoas muscle and lumbar plexus. Extreme Lateral Interbody Fusion (XLIF). Goodrich JA, Volcan IJ (ed): Quality Medical Publishing, Inc, St. Louis; 2013. 11-21.

28. Berjano P, Lamartina C: Far lateral approaches (XLIF) in adult scoliosis . Eur Spine J. 2013, 22:S242-53. 10.1007/s00586-012-2426-5 